University of Windsor

Scholarship at UWindsor

$1-2015$

\title{
Efficient aircraft spare parts inventory management under demand uncertainty
}

Jingyao Gu

University of Windsor

Guoqing Zhang

University of Windsor

Kevin Li

University of Windsor

Follow this and additional works at: https://scholar.uwindsor.ca/odettepub

Part of the Business Commons

\section{Recommended Citation}

Gu, Jingyao; Zhang, Guoqing; and Li, Kevin. (2015). Efficient aircraft spare parts inventory management under demand uncertainty. Journal of Air Transport Management, 42, 101-109.

https://scholar.uwindsor.ca/odettepub/96

This Article is brought to you for free and open access by the Odette School of Business at Scholarship at UWindsor. It has been accepted for inclusion in Odette School of Business Publications by an authorized administrator of Scholarship at UWindsor. For more information, please contact scholarship@uwindsor.ca. 


\title{
Efficient Spare Parts Inventory Management for Aircraft Maintenance
}

\author{
${ }^{1}$ Jingyao Gu, ${ }^{2}$ Guoqing Zhang*, ${ }^{3}$ Kevin Li \\ ${ }^{1,2}$ Supply Chain and Logistics Optimization Research Lab, Faculty of Engineering, \\ University of Windsor, Windsor, ON, Canada \\ ${ }^{3}$ Odette School of Business, University of Windsor, Windsor, ON, Canada
}

* Corresponding author, Tel: 519-253-3000 Ext. 2637, Fax: 519-973-7062

Email addresses: gzhang@uwindsor.ca 
Highlights of main contributions of this research:

- We introduce parts failure distribution into the spare parts inventory management problem. Compared with the traditional forecasting methods based on past demand data, this new approach predicts the future demand more accurate.

- Our proposed models satisfy spare parts demands from two perspectives: quantity and time. Therefore, it can better improve service level and control the total costs which generally include purchasing cost, holding cost, and shortage cost.

- Two nonlinear programming (NLP) formulations are established and two solution methodologies, GAMS and an iterative method are developed. Comparisons of the two models and solution methodologies are also discussed. 


\title{
Efficient Aircraft Spare Parts Inventory Management under Demand Uncertainty
}

\begin{abstract}
In airline industries, the aircraft maintenance cost takes up about $13 \%$ of the total operating cost. It can be reduced by a good planning. Spare parts inventories exist to serve the maintenance planning. Compared with commonly used reorder point system (ROP) and forecasting methods which only consider historical data, this paper presents two non-linear programming models which predict impending demands based on installed parts failure distribution. The optimal order time and order quantity can be found by minimizing total cost. The first basic mathematical model assumes shortage period starts from mean time to failure (MTTF). An iteration method and GAMS are used to solve this model. The second improved mathematical model takes into account accurate shortage time. Due to its complexity, only GAMS is applied in solution methodology. Both models can be proved effective in cost reduction through revised numerical examples and their results. Comparisons of the two models are also discussed.
\end{abstract}

Keywords: aircraft maintenance; spare parts; inventory management; non-linear programming; failure distribution; iteration method

\section{Introduction}

In airline industries, an operator has to deal with two types of issues: the aircraft operating cost and customer satisfaction. Aircraft maintenance planning plays a major role in both of them. On the one hand, based on an analysis in 2012 conducted by the International Air Transport Association (IATA)'s Maintenance Cost Task Force, the maintenance cost takes up about 13\% of the total operating cost, and it can be reduced by a good planning. On the other hand, an excellent maintenance program can effectively avoid flight delays and cancellations, thus improve customer satisfaction and competitiveness in the industry. Spare parts inventories exist to serve the maintenance planning. An excess of spare parts inventory leads to a high holding cost and impedes cash flows, whereas inadequate spare parts can result in costly flight cancellations or delays with a negative impact on airline performance. Since the airline industry involves with a large number of parts and some of them are quite expensive, it is important to find an appropriate inventory model to achieve a right balance. 


\begin{tabular}{|c|c|}
\hline Rotables & $\begin{array}{l}\text { Complex components } \\
\text { Normally unlimited number of repairs } \\
\text { Normally no scrap is expected } \\
\text { Controlled by individual serial number } \\
\text { Exchange during maintenance }\end{array}$ \\
\hline Repairables & $\begin{array}{l}\text { components which can be technically and economically repaired: } \\
\text { Under normal conditions, a follow up of each individual serial number is not necessary. } \\
\text { Have limited number of repairs and also have a possibility of scrap }\end{array}$ \\
\hline Expendables & $\begin{array}{l}\text { cannot be repaired and will be scrapped after removal and inspection result is unserviceable } \\
100 \% \text { replacement items } \\
\text { Items which cannot be repaired (not economical to be repaired) } \\
\text { Standard parts }\end{array}$ \\
\hline Consumables & $\begin{array}{l}\text { any materials used only once } \\
\text { Raw material } \\
\text { Chemical material } \\
\text { Items which merge on production with new product and cannot be removed }\end{array}$ \\
\hline
\end{tabular}

Table 1. Definitions of Rotables, Repairables, Expendables and Consumables

Compared with other industries, the airline industry is unique due to a combination of four market characteristics: global need for parts, demand unpredictability, traceability of parts for safety reasons, and high cost of not having a part. Traditionally, spare parts are generally classified into four groups: Rotables, Repairables, Expendables and Consumables, which are listed in Table 1. For different categories, different replenishment policies are used. Rotables and Repairables are mainly based on predicted failures estimated by manufacturers, and the planning parameters are finished as management decision. As to Expendables and Consumbles, the reorder point system (ROP) is used and input comes from historical demand with estimated changes. However, this kind of inventory management is typically subjective and imprecise, thus is not an ideal policy. From a survey conducted by Ghobbar and Friend (2004), 152 out of 175 respondents were using the ROP system and about half were dissatisfied and considering implementing new systems.

Our research was motivated by creating an efficient spare parts inventory model in order to provide 
better service for maintenance needs. When aircraft parts fail, they generate demand for spare parts, and are supplied from spare parts inventory. Under ideal situation, those parts should be in stock and in turn replenished by further activities such as purchasing or repairing. Demands will be satisfied immediately, and aircraft maintenance work can take place on schedule. However, if required spare parts are not available at that time, even purchase orders can be accepted by suppliers at once, delivery time is still a big issue that cannot be ignored. Postponed troubleshooting due to spare parts shortage will probably lead to flight delay or cancellation which will incur huge extra cost. Unfortunately, the second situation is hard to avoid because of uncertain parts failures, large number of parts, limit budget and warehouse space, etc. We try to establish an efficient spare parts inventory model that use minimum expense to achieve maximum productivity. Unlike the previous inventory models that just address the problem of determining the amount of parts to be purchased, our efficient inventory model satisfies spare parts demands from two perspectives: quantity and time. Therefore, it can better improve service level and control the total costs which generally include purchasing cost, holding cost, and shortage cost.

In the context of our model, the installed parts failure distribution is introduced. We assume failures can be predicted based on maintenance data or manufacturer's manual, and maintenance activities are the key drivers of spare parts demand. Advance orders are triggered to reduce downtime caused by parts delivery time. In our analysis, we examine the parts failure distribution to find optimal order time and order quantity by considering that the lifetime and quantity of installed parts failure distribution may influence the duration and numbers of spare parts shortage or overstock, thus result to total cost fluctuation. A non-linear programming (NLP) model is presented with the objective of minimizing air carriers' expected cost in spare parts. Numerical and iteration methods and GAMS are employed to solve the model.

This paper is organized as follows. In the next section, we give a brief literature review. Section 3 presents a basic mathematical model considering shortage period starts from mean time to failure (MTTF). Numerical and iteration methods as well as GAMS can be used to solve this model. We also develop an improved mathematical model, which takes into account exact shortage time, and its 
solution methodology in Section 4. Section 5 illustrates the value of our models in cost reduction by numerical examples and their results. Sensitivity analysis and models comparison is conducted in the following section. Finally, Section 7 provides the conclusions and suggestions for future research.

\section{Literature Review}

Over the past few decades, great efforts have been made to improve spare parts inventory management. Some research did demand forecast based on spare parts consumption in the past years. Among those work, Ghobbar and Friend (2003) discussed the forecasting of intermittent demand in relation to these primary maintenance processes, and compared the experimental results of thirteen forecasting methods. Regattieri et al. (2005) analyzed the behavior of forecasting techniques when dealing with lumpy demand, and made a comparison for twenty forecasting techniques. Both papers found that the best approaches for intermittent demand are weighted moving average, Holt and Croston methods.

In some other research, flying hours was considered as a critical factor in demand forecast. This is due to the fact that long flying hours may cause aging or wearout which closely relates to part failure or demand. Campbell (1963) examined demand data from the United State Air Force's maintenance records, and explored relationships between demand and operational variables. He concluded that demand seemed to be related to flying hours and sorties flown, with flying hours having a stronger relationship. Ghobbar and Friend (2002) investigated the source of demand lumpiness, and proposed an assumption that demand is strictly linearly to flying hours/landings. Today, more companies are considering flying hours as the major factor in their forecasting of demand calculation and using the mean time between removal/ overhaul (MTBR/O) to forecast a failure rate. Thus preventive maintenance (PM) is widely used especially for some critical components that directly affect flight safety.

Many papers are presented to address spare parts and failure-based maintenance actions or spare parts with either an age or block-based replacement policy. The earliest papers can be traced to Natarajan (1968) who proposed a reliability problem with spares and Allen and D'esopo (1968) who 
studied an ordering policy for repairable stock items. Armstrong and Atkins (1996) and de SmidtDestombes (2007) described the joint optimization of spare parts inventory and age or block-based replacement policies. Vaughan (2005) proposed a failure replacement and PM spare parts ordering policy. Wang (2012) presents a model to optimize the order quantity, order intervals, and PM intervals jointly under a two-stage failure process.

The aforesaid papers mainly address the problem either from an inventory point of view based on the past spare parts usages to forecast the future demand, or from a maintenance point of view to find an optimal order quantity and PM interval considering the correlation between flying hours and failures. To the author's best knowledge, limited research handles failure-based procurement inventory management which is very common in practice. One the one hand, when demand is triggered by failures, the demand forecast result based on past consumption may not be accurate. For example, past low demand in many periods may indicate significant parts aging and therefore high impending demands, but the traditional replenishment system will scale back replenishment which is counter to the actual requirement. One the other hand, PM inventory management is different from failure-based inventory management. As the spare parts demand is uncertain, and sometimes the part delivery time may be very long, it could lead significant loss if a critical part fails but there is no spare to replace it.

Deshpande et al. (2006) explored this issue. To improve the performance of aircraft service parts supply chain in the United States Coast Guard (USCG), they used mathematical programming tools to link the demand transactions to a corresponding maintenance activity. Subsequently, they developed an approach to use part-age data to make inventory decisions. It sets an age threshold and observes the number of installed parts whose age is greater than the threshold, thereby deciding the advance order quantity in the end of the observation period. This approach tries to synchronize the inventory of good parts with demand distributions, and replenish the inventory just as anticipated demands arrive. It has great advantages compared with traditional inventory policies. However, one important operational problem is not mentioned- when is the best time to issue orders? Ordering at the beginning of period will result in high holding cost, whereas replenishing at the end of period may lead to extensive shortage cost, both tend to drive up the total cost. Our proposed model considers both 
order time and order quantity. Furthermore, in Deshpande et al. (2006), based on the assumption that lead-time demand $D$ and the signal level $S$ follow a joint bivariate-normal distribution, they derived a result that the total cost per unit time is minimized by setting the part-age threshold $T$ to a value that maximizes the correlation $\rho(T)$ between $D$ and $S$. In contrast, we introduce the parts failure distribution from two aspects, life time and total number of failures, and assume they are uncorrelated, that is, $\rho$ equals to 0 . Because all demands come from installed parts failures, we can predict impending demands and develop an efficient proactive inventory model to replenish spare parts inventory before most failures occur. Accordingly, the best order time and the optimal order quantities can be worked out by minimizing the total cost which consists of purchasing, holding, and shortage costs.

\section{Basic Mathematical Model and Solution Methodology}

\subsection{Basic Mathematical Model}

In this paper, we consider a generalized ordering policy for only one kind of part with a given part number (PN) in a single period. A part number is a fundamental identifier of a particular part design used in the airline industry. It unambiguously identifies a part design within a single corporation, or sometimes across several corporations. For example, when specifying a bolt, it is easier to refer to "PN BACB30LH3K24" than describing the key information of the bolt, such as dimensions, material, installed position and manufacturer, which may be lengthy and incomplete. Moreover, multiple parts with the same PN are often found in one or more aircrafts. For instance, if one Boeing 737-300 has installed 200 PN BACB30LH3K24 bolts, and the fleet size of Boeing 737-300 is 20, thus the total number of PN BACB30LH3K24 operated by the carrier will be 4000 .

The length of the planning horizon is denoted by $T(0 \leq T \leq \infty)$ and the order quantity in this period is denoted by $\mathrm{Q}$. The spare parts for replacement can be delivered after a constant lead time $\mathrm{L}$. The demand is uncertain, and depends on the parts failure distribution. We assume that the number of failures in period $\mathrm{T}$ follows a probability density function (PDF) $\mathrm{g}(\cdot)$ and a cumulative distribution function (CDF) G (•). The lifetimes of the operating parts are assumed independent with an identical probability density function $f(\cdot)$ and a cumulative distribution function $F(\cdot)$. We also assume $g(\cdot)$ and $f$ $(\cdot)$ are uncorrelated. 
Input parameters and function:

$h \quad$ the unit holding cost per unit time

$s \quad$ the unit shortage cost per unit time

$T \quad$ planning horizon, can be infinite

$L \quad$ order lead time

$z \quad$ demand quantity, a random variable

c unit cost

$f(x)$ the PDF of failure distribution considering lifetime for each part

$g(z)$ the PDF of failure distribution considering number of failures for each PN

$F(x)$ the CDF of failure distribution considering lifetime for each part

$G(z)$ the CDF of failure distribution considering number of failures for each PN

Define the following decision variables

$t_{1}$ point in time to place an order

$t_{2} \quad$ the parts arrival time

$Q \quad$ order quantity

The objective of minimizing the expected total cost is formulated as:

$$
\begin{aligned}
\operatorname{Min} R= & h\left(T-t_{2}\right) \int_{0}^{Q}(Q-z) g(z) d z+s\left[T-\int_{0}^{\infty} x f(x) d x\right] \int_{Q}^{\infty}(z-Q) g(z) d z+ \\
& {\left[h \int_{t_{2}}^{\infty}\left(x-t_{2}\right) f(x) d x+s \int_{0}^{t_{2}}\left(t_{2}-x\right) f(x) d x\right] Q+c Q }
\end{aligned}
$$

In the whole planning horizon, we just order this given PN once. If the order quantity is above the total actual demand level, that is, the total number of failures in the whole planning horizon is less than the order quantity $Q$, the holding cost of those extra stock will start from $t_{2}$ and last till the end of the period. The expected holding cost of this part is represented by the first term. Conversely, if the order quantity $Q$ is below the total number of failures, the parts shortage situation will last till the end of the planning horizon. The second term describes this expected shortage cost. Notice that the duration of 
parts shortage is decided by when the $Q^{\text {th }}$ failure occurs and when the planning horizon finishes. This basic model simplifies the problem by using the mean time to failure (MTTF), which is defined by MTTF $=\int_{0}^{\infty} x f(x) d x$, to replace the $Q^{\text {th }}$ failure time. The third term depicts the expected value of the remaining holding cost and shortage cost during the planning horizon when the order quantity " $Q$ " just matches the total number of failures. Figure 1 illustrates how this part of holding cost and shortage cost are generated. For example, if five failures occurred during the whole planning horizon $\mathrm{T}$, and purchased parts arrived between the third failure and the fourth failure, shortage cost would be incurred due to the first three failures. On the other hand, the remaining ordered parts would be kept in stock and continuously generate holding cost until they are used up. The last term accounts for the purchasing cost. Once we find the optimal parts arrival time, the optimal timing to place an order can be calculated easily by $t_{1}=t_{2}-L$.

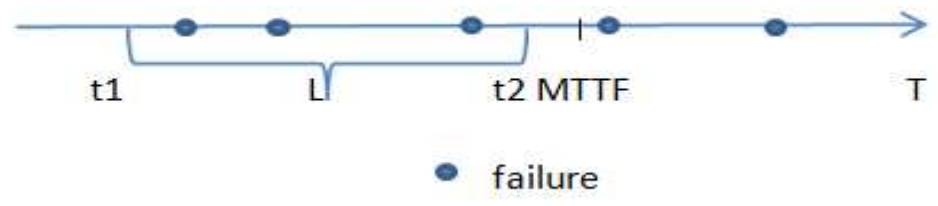

Figure 1. Time sequence

\subsection{Solution Methodology}

\subsubsection{Numerical and iteration methods}

From objective function (1), we are obviously interested in determining the value of $t_{2}$ and $Q$, which minimize the expected cost $R$. Without considering any constraint, $Q$ and $t_{2}$ can be found by the following procedure:

$$
\begin{aligned}
\frac{\partial R}{\partial Q}=h\left(T-t_{2}\right) & G(Q)-s\left[T-\int_{0}^{\infty} x f(x) d x\right][1-G(Q)] \\
+ & {\left[h \int_{t_{2}}^{\infty}\left(x-t_{2}\right) f(x) d x+s \int_{0}^{t_{2}}\left(t_{2}-x\right) f(x) d x\right]+c }
\end{aligned}
$$

It follows that 
$\frac{\partial^{2} \mathrm{R}}{\partial \mathrm{Q}^{2}}=\left\{h\left(T-t_{2}\right)+s\left[T-\int_{0}^{\infty} x f(x) d x\right]\right\} g(Q) \geq 0$, for all $\mathrm{Q} \geq 0$

Because the second-order derivative is nonnegative, the function $R(Q)$ is said to be convex. The optimal solution, $Q^{*}$, occurs where $\frac{\partial R}{\partial Q}$ equals zero. That is,

$G\left(Q^{*}\right)=\frac{s\left[T-\int_{0}^{\infty} x f(x) d x\right]-\left[h \int_{t_{2}}^{\infty}\left(x-t_{2}\right) f(x) d x+s \int_{0}^{t_{2}}\left(t_{2}-x\right) f(x) d x\right]-c}{h\left(T-t_{2}\right)+s\left[T-\int_{0}^{\infty} x f(x) d x\right]}$

Also,

$\frac{\partial R}{\partial t_{2}}=-h \int_{0}^{Q}(Q-z) g(z) d z-Q h\left[1-F\left(t_{2}\right)\right]+Q s F\left(t_{2}\right)$

It follows that

$\frac{\partial^{2} \mathrm{R}}{\partial t_{2}{ }^{2}}=Q f\left(t_{2}\right)(h+s) \geq 0$, for all $\mathrm{Q} \geq 0$.

As the second-order derivative is nonnegative, $\mathrm{R}\left(t_{2}\right)$ is convex, and the optimal solution, $t_{2}{ }^{*}$, is attained when $\frac{\partial R}{\partial t_{2}}$ equals zero. That is,

$F\left(t_{2}^{*}\right)=\frac{h \int_{0}^{Q}(Q-z) g(z) d z+Q h}{Q(h+s)}$

One of the widely-used probability distributions in reliability to model fatigue and wear-out phenomena is the normal distribution, as illustrated by the works of Tuomas et al. (2001), Byington et al. (2002), Batchoun et al. (2003), Deshpande et al. (2006), Muchiri and Smit (2011), and Kiyak (2012). If we assume that $f(x)$ is normally distributed, with a mean $\mu_{x}$ and standard deviation $\sigma_{x}$, the formula for the PDF is

$f(x)=\frac{1}{\sqrt{2 \pi} \sigma_{\mathrm{x}}} \exp \left[-\frac{1}{2} \frac{\left(x-\mu_{\mathrm{x}}\right)^{2}}{\sigma_{\mathrm{x}}^{2}}\right], \quad-\infty<x<\infty$

Meanwhile, assume $\mathrm{g}(\mathrm{z})$ follows a normal distribution with a mean $\mu_{\mathrm{z}}$ and standard deviation $\sigma_{\mathrm{z}}$. The formula for the PDF is

$g(z)=\frac{1}{\sqrt{2 \pi} \sigma_{\mathrm{z}}} \exp \left[-\frac{1}{2} \frac{\left(z-\mu_{\mathrm{z}}\right)^{2}}{\sigma_{\mathrm{z}}^{2}}\right], \quad-\infty<z<\infty$ 
As the random variable ranges from $-\infty$ to $+\infty$, the normal distribution is not a true reliability distribution. However, if for most observed values of mean and standard deviation in the context of this study, the probability that the random variable takes on negative values is negligible, then the normal distribution can be regarded as a reasonable approximation to a failure process. We assume $0<x<\infty, 0<z<\infty$, also $\mathrm{f}(\mathrm{x})$ and $\mathrm{g}(\mathrm{z})$ are uncorrelated.

From Equation (3), we have

$Q^{*}=G^{-1}\left\{\frac{s\left(T-\mu_{\mathrm{X}}\right)-\mathrm{h}\left(\mu_{\mathrm{x}}-t_{2}\right)-(h+s)\left[\left(t_{2}-\mu_{\mathrm{X}}\right) F_{S}\left(\frac{t_{2}-\mu_{\mathrm{x}}}{\sigma_{\mathrm{X}}}\right)+\sigma_{\mathrm{x}} f_{s}\left(\frac{t_{2}-\mu_{\mathrm{X}}}{\sigma_{\mathrm{X}}}\right)\right]-c}{h\left(T-t_{2}\right)+s\left(T-\mu_{\mathrm{x}}\right)}\right\}$

Here $f_{S}(\cdot)$ is the standard normal density function, and $F_{S}(\cdot)$ is the standard normal cumulative distribution function for the normal density function $f(x) \cdot G^{-1}(\cdot)$ is the inverse of the cumulative density function for the normal density function $g(z)$.

From Equation (5), we have

$t_{2}^{*}=F^{-1}\left\{\frac{h\left(Q-\mu_{\mathrm{z}}\right) G_{s}\left[\frac{\left(Q-\mu_{\mathrm{Z}}\right)}{\sigma_{\mathrm{Z}}}\right]+h \sigma_{\mathrm{z}} g_{s}\left[\frac{\left(Q-\mu_{\mathrm{Z}}\right)}{\sigma_{\mathrm{Z}}}\right]+Q h}{Q(h+s)}\right\}$

Here $g_{s}(\cdot)$ is the standard normal density function, and $G_{s}(\cdot)$ is the standard normal cumulative distribution function for the normal density function $g(z) . F^{-1}(\cdot)$ is the inverse of the cumulative density function for the normal density function $f(x)$.

Because $Q^{*}$ and $t_{2}{ }^{*}$ cannot be determined in closed forms from (6) and (7), a numerical algorithm is employed to find solutions. The algorithm converges in a finite number of iterations, provided that a feasible solution exists. The algorithm is described as follows:

Step 0. Use the initial solution $Q_{1}=Q^{*}=G^{-1}\left\{\frac{s\left(T-\mu_{\mathrm{x}}\right)-\mathrm{h}\left(\mu_{\mathrm{x}}-t_{2}\right)-(h+s)\left[\left(t_{2}-\mu_{\mathrm{x}}\right) F_{s}\left(\frac{t_{2}-\mu_{\mathrm{x}}}{\sigma_{\mathrm{X}}}\right)+\sigma_{\mathrm{x}} f_{s}\left(\frac{t_{2}-\mu_{\mathrm{x}}}{\sigma_{\mathrm{x}}}\right)\right]-c}{h\left(T-t_{2}\right)+s\left(T-\mu_{\mathrm{x}}\right)}\right\}$, and let $t_{2}^{(0)}=0$. Set $\mathrm{i}=1$, and go to step $\mathrm{i}$.

Step i. Use $Q_{i}$ to determine $t_{2}^{(i)}$ from Equation (7). If $t_{2}^{(i)} \approx t_{2}^{(i-1)}$, stop; the optimal solution is $Q^{*}=Q_{i}$, and $t_{2}^{*}=t_{2}^{(i)}$. Otherwise, use $t_{2}^{(i)}$ in Equation (6) to compute $Q_{i}$. Set $\mathrm{i}=\mathrm{i}+1$, and repeat step $\mathrm{i}$. 
When the iteration terminates, we can find the optimal timing to place an order as $t_{1}=t_{2}{ }^{*}-L$.

To facilitate the calculation of the objective function value in the basic model in the numerical experiment, Equation (1) can be simplified as:

$$
\begin{aligned}
\operatorname{Min} R= & h\left(T-\mathrm{t}_{2}\right)\left\{\left(Q-\mu_{\mathrm{z}}\right) G_{s}\left[\frac{\left(Q-\mu_{\mathrm{z}}\right)}{\sigma_{\mathrm{z}}}\right]+\sigma_{\mathrm{z}} g_{s}\left[\frac{\left(Q-\mu_{\mathrm{z}}\right)}{\sigma_{\mathrm{z}}}\right]\right\} \\
& +s\left(T-\mu_{\mathrm{x}}\right)\left\{\left(\mu_{\mathrm{z}}-Q\right)\left[1-G_{s}\left(\frac{Q-\mu_{\mathrm{z}}}{\sigma_{\mathrm{z}}}\right)\right]+\sigma_{\mathrm{z}} g_{s}\left[\frac{\left(Q-\mu_{\mathrm{z}}\right)}{\sigma_{\mathrm{z}}}\right]\right\} \\
& +\mathrm{h}\left(\mu_{\mathrm{x}}-t_{2}\right) Q+(h+s) Q\left\{\left(t_{2}-\mu_{\mathrm{x}}\right) F_{s}\left[\frac{\left(t_{2}-\mu_{\mathrm{x}}\right)}{\sigma_{\mathrm{x}}}\right]+\sigma_{\mathrm{x}} f_{s}\left[\frac{\left(t_{2}-\mu_{\mathrm{x}}\right)}{\sigma_{\mathrm{x}}}\right]\right\}+c Q
\end{aligned}
$$

If the part failure process for a given part number follows other distributions, we can find the corresponding solution by solving Equations (3) and (5) with the suitable distribution function.

\subsubsection{Solve the basic model by GAMS}

Another method is to use the function errorf(·) in GAMS to implement the non-linear integral component of the objective function and find an optimal solution. Both MINOS and CONOPT can yield good results. MINOS is suitable for large constrained problems with a linear or nonlinear objective function and a mixture of linear and nonlinear constraints. For nonlinear constraints, MINOS implements a sequential linearly constrained algorithm derived from the Robinson's method. CONOPT is a feasible path solver based on the generalized reduced gradient method and is often preferable for nonlinear models where feasibility is difficult to achieve.

\section{An Improved Mathematical Model and Solution Methodology}

In the basic model presented in the previous section, the value of T minus MTTF instead of the $Q^{\text {th }}$ failure time is adopted to define the parts shortage period till the end of the planning horizon. The improved mathematical model herein aims to find when the $Q^{\text {th }}$ failure occurs and plugs it into the model. Therefore, this improved model is designed to find more accurate order quantity $\mathrm{Q}$ and order time $t_{2}$. 
In reliability engineering, it is well known that given that $t_{1}, t_{2}, \ldots, t_{n}$, where $t_{i} \leq t_{i+1}$, are $n$ ordered failure times comprised in a random sample, the number of units surviving at time $t_{i}$ is $n$-i. A possible estimate for the reliability function can be expressed as

$\hat{R}\left(\mathrm{t}_{\mathrm{i}}\right)=\frac{n-i}{n}=1-\frac{i}{n}$.

The estimate for the cumulative failure distribution is

$\hat{F}\left(\mathrm{t}_{\mathrm{i}}\right)=1-\hat{R}\left(\mathrm{t}_{\mathrm{i}}\right)=\frac{i}{n}$.

If we assume the total number of parts with a given PN in the observed fleet is $n$, which is technical information provided by the original equipment manufacturer (OEM), and $\mathrm{t}_{Q}$ is the $Q^{\text {th }}$ failure time, $Q \ll n$. We also assume that $\mathrm{f}(\mathrm{x})$ is normally distributed, and the failure times follow $t_{i} \sim N\left(\mu_{x}, \sigma_{x}{ }^{2}\right)$, then

$F\left(t_{i}\right)=\Phi\left(\frac{t_{i}-\mu_{\mathrm{x}}}{\sigma_{\mathrm{x}}}\right)$.

Because $\hat{F}\left(\mathrm{t}_{Q}\right)=\frac{Q}{n^{\prime}}$ and $F\left(\mathrm{t}_{Q}\right)=\Phi\left(\frac{\mathrm{t}_{Q}-\mu_{\mathrm{x}}}{\sigma_{\mathrm{x}}}\right)$,

we have

$\frac{Q}{n}=\Phi\left(\frac{\mathrm{t}_{Q}-\mu_{\mathrm{x}}}{\sigma_{\mathrm{x}}}\right)$. That is, $Q=n \Phi\left(\frac{\mathrm{t}_{Q}-\mu_{\mathrm{x}}}{\sigma_{\mathrm{x}}}\right)$.

Accordingly, the $Q^{\text {th }}$ failure time can be expressed as

$\mathrm{t}_{Q}=\sigma_{\mathrm{x}} * F_{S}^{-1}\left(\frac{Q}{n}\right)+\mu_{\mathrm{x}}$

and Equation (1) can be improved as

$$
\begin{aligned}
\operatorname{Min} R= & h\left(T-t_{2}\right) \int_{0}^{Q}(Q-z) g(z) d z+s \int_{Q}^{\infty}\left[T-\sigma_{\mathrm{x}} * F_{S}^{-1}\left(\frac{z}{n}\right)-\mu_{\mathrm{x}}\right](z-Q) g(z) d z+ \\
& {\left[h \int_{t_{2}}^{\infty}\left(x-t_{2}\right) f(x) d x+s \int_{0}^{t_{2}}\left(t_{2}-x\right) f(x) d x\right] Q+c Q . }
\end{aligned}
$$

It is too difficult to determine $\mathrm{Q}^{*}$ and $t_{2}{ }^{*}$ from Equation (10) due to the complexity of the second term. To simplify the formulation, we propose Equation (11) as below, where the second term on shortage cost is approximately expressed by using the $Q^{\text {th }}$ failure time.

$\operatorname{Min} R=h\left(T-t_{2}\right) \int_{0}^{Q}(Q-z) g(z) d z+s\left[T-\sigma_{\mathrm{x}} * F_{S}^{-1}\left(\frac{Q}{n}\right)-\mu_{\mathrm{x}}\right] \int_{Q}^{\infty}(z-Q) g(z) d z+$ 


$$
\left[h \int_{t_{2}}^{\infty}\left(x-t_{2}\right) f(x) d x+s \int_{0}^{t_{2}}\left(t_{2}-x\right) f(x) d x\right] Q+c Q
$$

Compared with Equation (1), Equation (11) is still much more complex due to the inverse function

$F_{S}^{-1}\left(\frac{Q}{n}\right)$, and it is hard to be solved by iterative method. However, with the simplification, we can use GAMS and its solver CONOPT to solve the problem (11). Numerical examples and comparative results of the two models are conducted in next section.

\section{Numerical Examples and Results}

A numerical example, which is introduced in Deshpande et al. (2006), is modified by introducing the distribution of the number of failures for a specified PN. The data are originally drawn from the aircraft maintenance and inventory databases of the United States Coast Guard (USCG) (Deshpande et al., 2006). Here we list the same parameter values used in Deshpande et al. (2006) in Table 2, which is about the main gearbox of aircraft type HH65A.

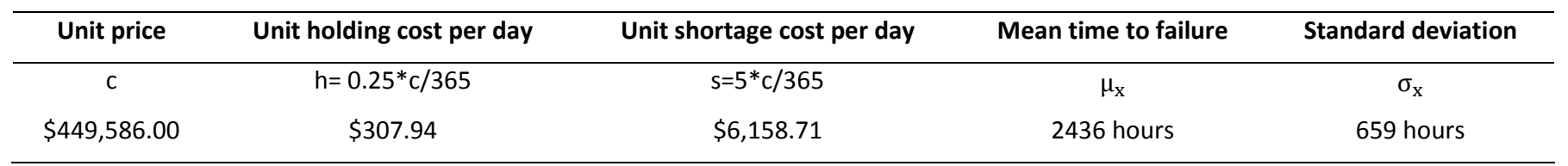

Table 2. Parameter values of main gearbox in Deshpande et al. (2006)

Note that if we assume a daily flying time of 10 hours, the gearbox mean age at failure should be $2436 / 10=243.6$ days, similarly the standard deviation should be $659 / 10=65.9$ days. Additional parameter values in Table 3 are introduced for our new models.

\begin{tabular}{cccc}
\hline Planning horizon & Mean number of failures & Standard deviation & Total number of parts observed in fleet \\
\hline $\mathrm{T}$ & $\mu_{\mathrm{z}}$ & $\sigma_{\mathrm{z}}$ & $\mathrm{n}$ \\
5 years $=1,825$ days & 25 & 10 & 200 \\
\hline
\end{tabular}

Table 3. New designed parameter values for main gearbox

Table 4 summarizes the calculation results of both the Iterative method and GAMS for the basic model, and of GAMS for the improved model. We can see that, for the basic model, the decision variables for both the Iterative approach and the GAMS approach produce very similar results. The objective 
function values for both approaches are slightly different with a percentage error margin of $0.45 \%$. This error is likely due to the assumption that $\int_{x=0}^{a} x f(x) d x \cong \int_{x=-\infty}^{a} x f(x) d x=\mu F_{S}\left[\frac{(a-\mu)}{\sigma}\right]-$ $\sigma f_{S}\left[\frac{(a-\mu)}{\sigma}\right]$ in the iterative approach, which neglects the part of the negative values in the normal distribution. On the other hand, both approaches yield almost identical decision variable values. Next we compare the differences of GAMS results between the basic and improved models. The values of $t_{2}$ are essentially the same for the models. However, the values of $Q$ and $R$ change to a certain degree. Compared with the basic model, the value of $Q$ for the improved model increases by $0.55 \%$, and the value of $\mathrm{R}$ increases by $0.54 \%$. A closer examination of the two objective functions reveals that the only difference exists in the second term: the shortage period described in the basic model is $\left(T-\mu_{\mathrm{x}}\right)$, while in the improved model it is $\left(T-\mathrm{t}_{Q}\right)=\left[T-\sigma_{\mathrm{x}} * F_{S}^{-1}\left(\frac{Q}{n}\right)-\mu_{\mathrm{x}}\right]$. Because the change is only related to $Q$ and $R$, it barely affects the optimal value of $t_{2}$. In this example, $t_{Q}$ is less than $\mu_{x}$ implying that the shortage situation starts a little earlier in the improved model than that in the basic model, therefore more shortage cost would be incurred and more spare parts should be ordered during the planning horizon.

\begin{tabular}{lcccc}
\hline \multicolumn{1}{c}{ Solution approach } & & Iterative & \multicolumn{2}{c}{ GAMS } \\
& & basic model & basic model & improved model \\
\hline Objective function value & $\mathrm{R}$ & $\$ 30,110,394.24$ & $\$ 29,974,161.85$ & $\$ 30,135,359.75$ \\
Decision variable & $\mathrm{Q}$ & 37.90 & 37.92 & 38.13 \\
& $\mathrm{t}_{2}$ & 143.52 & 143.41 & 143.48 \\
Iteration number & $\mathrm{t}_{Q}$ & $*$ & $*$ & 185.91 \\
Feasible solution & & 3 & 14 & 14 \\
\hline
\end{tabular}

Table 4. Results from iterative and GAMS solution approaches

In order to gain better insights into the proposed models and understand their values for cost reduction in reality, we input different values of $Q$ and $t_{2}$ in Equation (8) and then compare their objective function values. The basic model is chosen because its format is easier than the improved model whereas the calculation results of both models are comparable as illustrated in Table 4 . Figure 2 illustrates the relationship between the expected cost and parts arrival time for the main gear box when $Q=37.90$. The optimal value of parts arrival time, which minimizes the expected cost, should be 
set at 143.52. Based on the trend, as the parts arrival time increases, the expected cost first decreases slightly, followed by a dramatic increase. The reason is that, compared with the shortage cost, the holding cost only takes a small fraction of the unit cost. Moreover, the mean age at failure happens at the early period of the planning horizon.

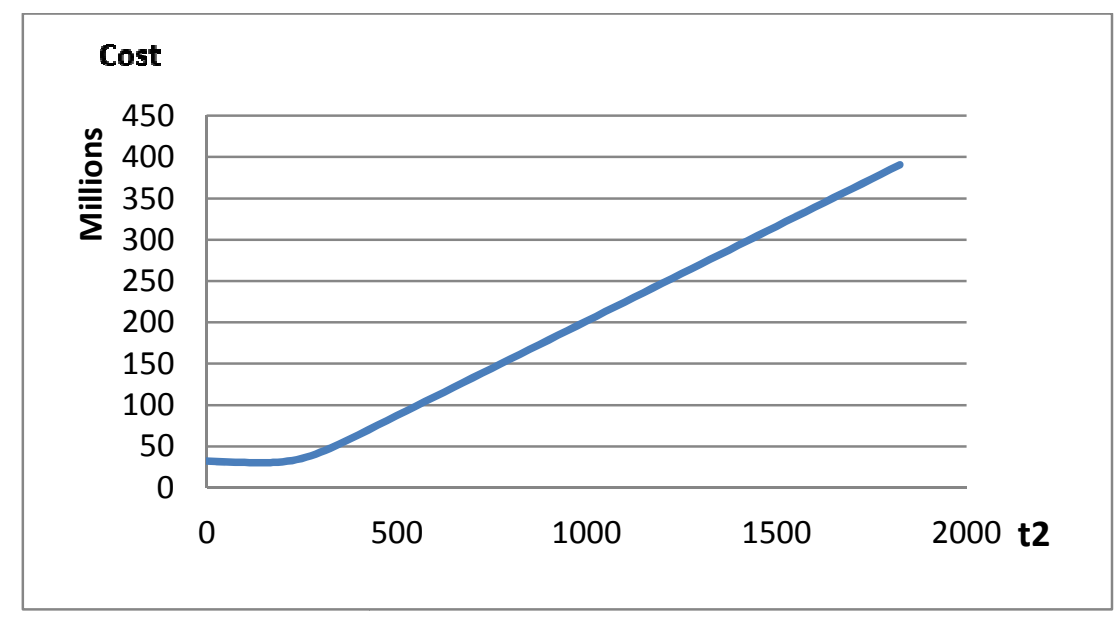

Figure 2. Cost vs. parts arrival time for main gearbox when $Q=37.90$

Figure 3 depicts the relationship between the expected cost and order quantity curve for the main gear box when $t_{2}=143.52$. From the figure, we can find that as the order quantity increases, the expected cost drops sharply till $Q=37.90$, then followed by a much slower gradual increase. The different slopes of the curve can be intuitively explained as follows: if the actual order quantity is below the optimal order quantity, compared with overstocking, the shortage cost is much higher than the holding cost.

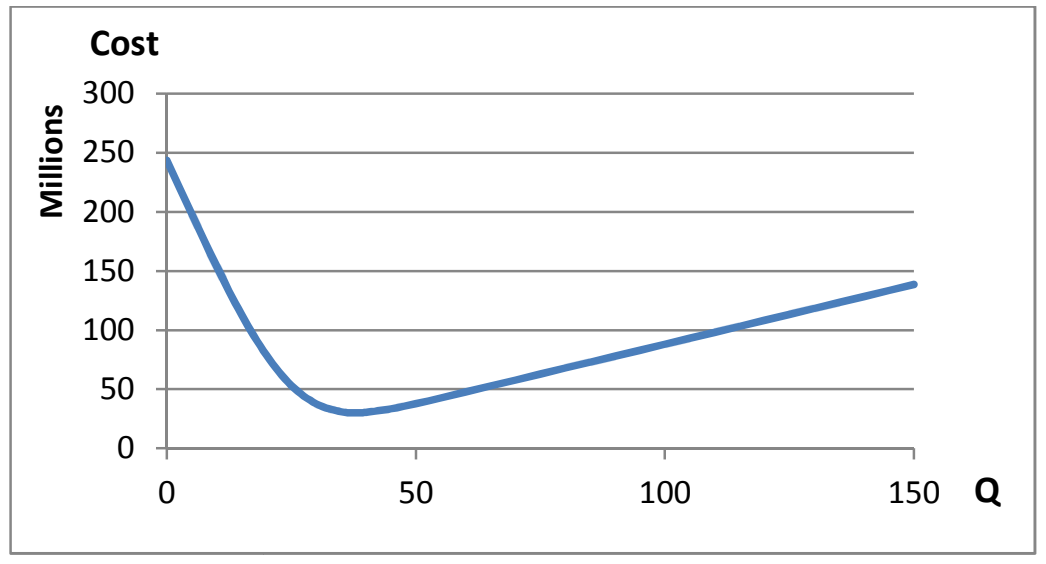

Figure 3. Cost vs. order quantity for gearbox when $t_{2}=143.52$ 


\section{Sensitivity Analysis and Comparison of Models}

To examine how critical parameters in the model affect the optimal solution, we conduct sensitivity analyses for two different cases and compare their final results between the basic model and improved model. The parameter values are based on the second example in Section 5. In each case, only one parameter is changed while the others are kept constant. We investigate how the optimal solutions (total cost $\mathrm{R}$, order quantity $\mathrm{Q}$, parts arrival time $\left.t_{2}\right)$ are affected by the failure distributions $\left(\mu_{\mathrm{x}}, \sigma_{\mathrm{x}}, \mu_{\mathrm{z}}\right.$, $\sigma_{z}$ ), and how $R, Q$, and $t_{2}$ in the improved model change with the total number of observed parts $(n)$.

First, we calculate the optimal objective values by varying $\mu_{x}$, the MTTF of given parts, as Table 5 shows. Figure 4 describes that the expected total cost $\mathrm{R}$ of both the basic and improved models decreases as $\mu_{\mathrm{x}}$ increases from 200 to 1200. Also, the values of $\mathrm{R}$ in the improved model are always higher than those in the basic model, at a small margin from $1.04 \%$ to $2.90 \%$. Figure 5 illustrates that the optimal order quantity $\mathrm{Q}$ in both models decreases when $\mu_{\mathrm{x}}$ increases. Compared with the basic model, the values of $Q$ in the improved model are higher, at a margin from $1.05 \%$ to $4.24 \%$. Figure 6 shows that the parts arrival time $t_{2}$ in both models increases when $\mu_{x}$ increases. The values of both $t_{2}$ are almost identical, verifying that the assertion in Section 2.5 that the two models mainly differ in their handling of $Q$ and $R$, and, hence the optimal value of $t_{2}$ is barely affected.

\begin{tabular}{cccccccccc}
\hline & \multicolumn{3}{c}{ Basic model } & \multicolumn{3}{c}{ Improved model } & \multicolumn{3}{c}{ Percentage Error } \\
$\mu_{\mathrm{x}}$ & $\mathrm{R}$ & $\mathrm{Q}$ & $\mathrm{t}_{2}$ & $\mathrm{R}$ & $\mathrm{Q}$ & $\mathrm{t}_{2}$ & $\mathrm{R}$ & $\mathrm{Q}$ & $\mathrm{t}_{2}$ \\
\hline 200 & 30080101 & 30.13 & 154.83 & 30395999 & 30.45 & 155.03 & $1.04 \%$ & $1.05 \%$ & $0.13 \%$ \\
400 & 28282093 & 29.72 & 354.36 & 28620638 & 30.09 & 354.60 & $1.18 \%$ & $1.24 \%$ & $0.07 \%$ \\
600 & 26433376 & 29.18 & 554.01 & 26802664 & 29.63 & 554.30 & $1.38 \%$ & $1.52 \%$ & $0.05 \%$ \\
800 & 24530299 & 28.45 & 753.55 & 24944128 & 29.02 & 753.91 & $1.66 \%$ & $1.96 \%$ & $0.05 \%$ \\
1000 & 22536336 & 27.40 & 952.89 & 23020242 & 28.17 & 953.37 & $2.10 \%$ & $2.71 \%$ & $0.05 \%$ \\
1200 & 20370771 & 25.75 & 1151.87 & 20980234 & 26.89 & 1152.57 & $2.90 \%$ & $4.24 \%$ & $0.06 \%$ \\
\hline
\end{tabular}

Table 5. Objective values comparison of two models when $\mu_{x}$ changes 


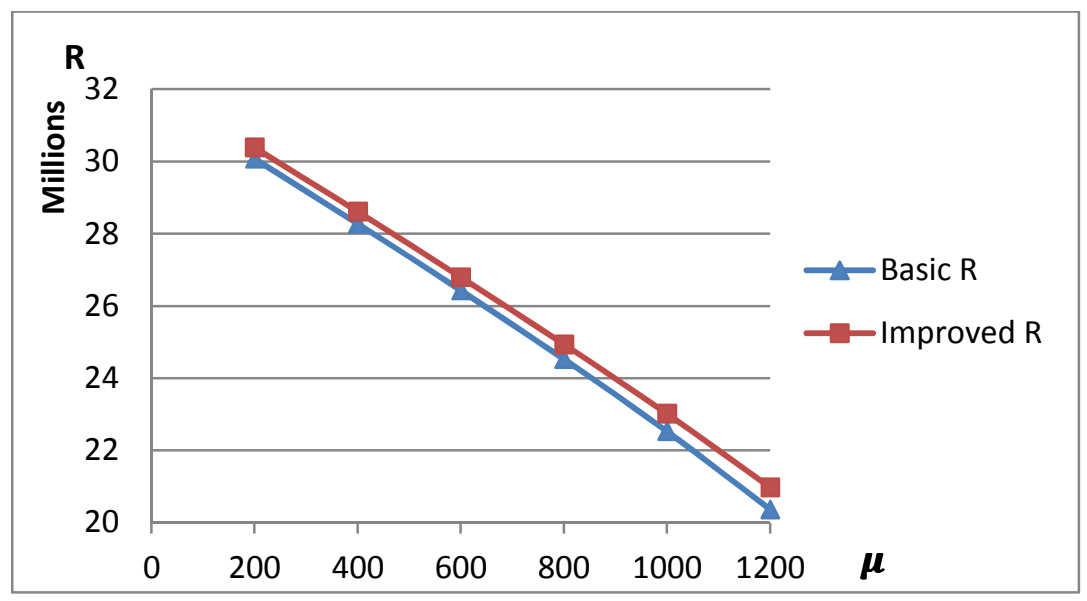

Figure 4. Total cost as $\mu_{\mathrm{x}}$ increases

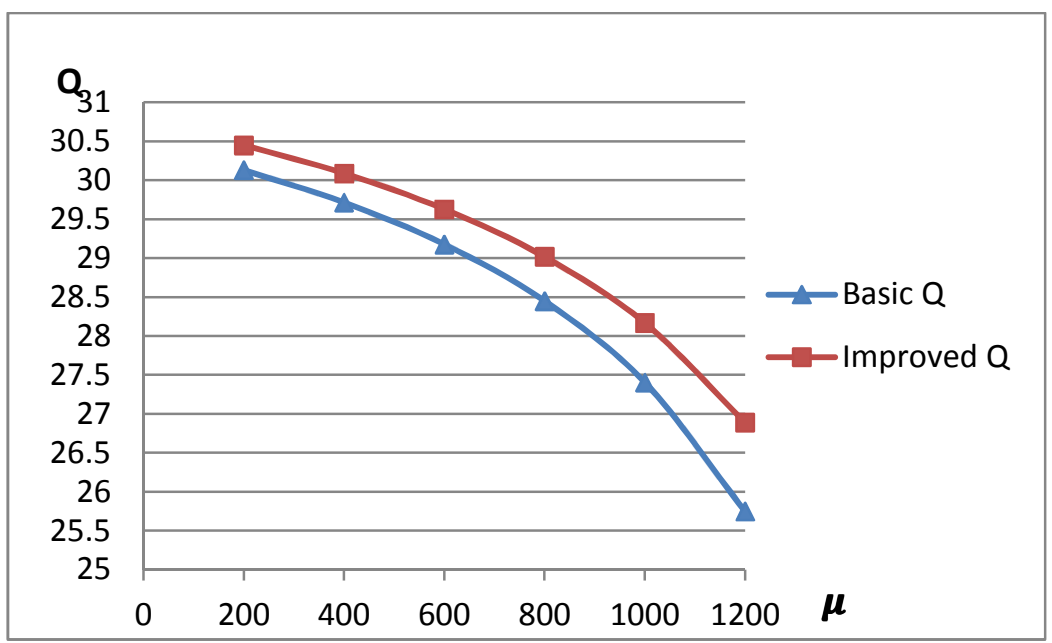

Figure 5. Optimal order quantity as $\mu_{\mathrm{x}}$ increases

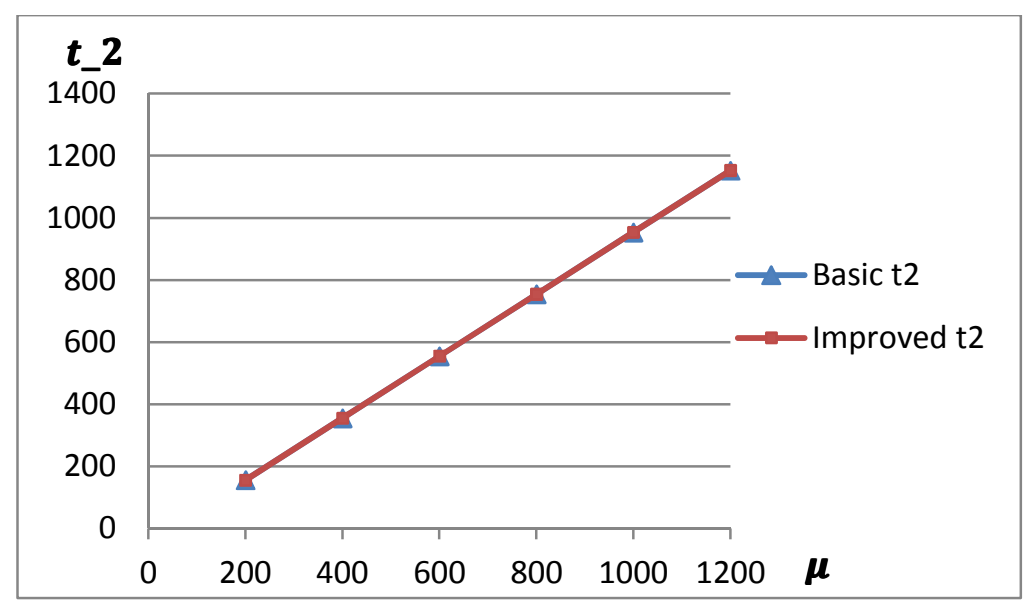

Figure 6. Optimal inventory replenishment time as $\mu_{\mathrm{x}}$ increases 


\begin{tabular}{cccccccccc}
\hline & \multicolumn{3}{c}{ Basic model } & \multicolumn{4}{c}{ Improved model } & \multicolumn{3}{c}{ Percentage Error } \\
$\sigma_{\mathrm{x}}$ & $\mathrm{R}$ & $\mathrm{Q}$ & $\mathrm{t}_{2}$ & $\mathrm{R}$ & $\mathrm{Q}$ & $\mathrm{t}_{2}$ & $\mathrm{R}$ & $\mathrm{Q}$ & $\mathrm{t}_{2}$ \\
\hline 20 & 19042951 & 26.23 & 1203.48 & 19225695 & 26.60 & 1203.55 & $0.95 \%$ & $1.40 \%$ & $0.01 \%$ \\
40 & 19534770 & 25.93 & 1188.85 & 19906533 & 26.67 & 1189.13 & $1.87 \%$ & $2.76 \%$ & $0.02 \%$ \\
60 & 20020055 & 25.64 & 1174.12 & 20587051 & 26.73 & 1174.72 & $2.75 \%$ & $4.08 \%$ & $0.05 \%$ \\
80 & 20498901 & 25.35 & 1159.28 & 21267288 & 26.78 & 1160.34 & $3.61 \%$ & $5.36 \%$ & $0.09 \%$ \\
100 & 20971401 & 25.06 & 1144.34 & 21947276 & 26.83 & 1145.97 & $4.45 \%$ & $6.62 \%$ & $0.14 \%$ \\
120 & 21437640 & 24.77 & 1129.3 & 22627043 & 26.88 & 1131.62 & $5.26 \%$ & $7.84 \%$ & $0.21 \%$ \\
140 & 21897695 & 24.49 & 1114.16 & 23306612 & 26.92 & 1117.28 & $6.05 \%$ & $9.04 \%$ & $0.28 \%$ \\
160 & 22351642 & 24.21 & 1098.93 & 23986003 & 26.97 & 1102.95 & $6.81 \%$ & $10.23 \%$ & $0.36 \%$ \\
180 & 22799548 & 23.93 & 1083.61 & 24665234 & 27.00 & 1088.64 & $7.56 \%$ & $11.38 \%$ & $0.46 \%$ \\
200 & 23241476 & 23.65 & 1068.2 & 25344320 & 27.04 & 1074.33 & $8.30 \%$ & $12.54 \%$ & $0.57 \%$ \\
\hline
\end{tabular}

Table 6. Objective values comparison of two models when $\sigma_{x}$ changes

Next, we consider the impact on the optimal objective value by changing the value of standard deviation $\left(\sigma_{\mathrm{x}}\right)$ of the parts lifetime, which is listed in Table 6. Figure 7 illustrates that the expected total cost $R$ of both the basic and improved models increases as $\sigma_{x}$ increases from 20 to 200 . This result is natural as a heightened uncertainty level tends to result in more holding and shortage costs. Figure 8 describes an interesting situation that the optimal order quantity $Q$ in the basic model decreases whereas that in the improved model increases when $\sigma_{\mathrm{x}}$ grows. The order quantity $\mathrm{Q}$ in the basic model is always higher than in the improved model. The reason might be that failures between $t_{Q}$ and $\mu_{\mathrm{x}}$ are ignored in the basic model, leading to a lower order quantity than that in the improved model. Furthermore, when $\sigma_{\mathrm{x}}$ increases, the failures distribution becomes flatter, accordingly more parts will be ordered earlier to guarantee the same service level. However, the optimal value of $Q$ in the basic model decreases due to a growing number of neglected failures between $\mathrm{t}_{Q}$ and $\mu_{\mathrm{x}}$. Finally, Figure 9 confirms that $t_{2}$ still has little change. 


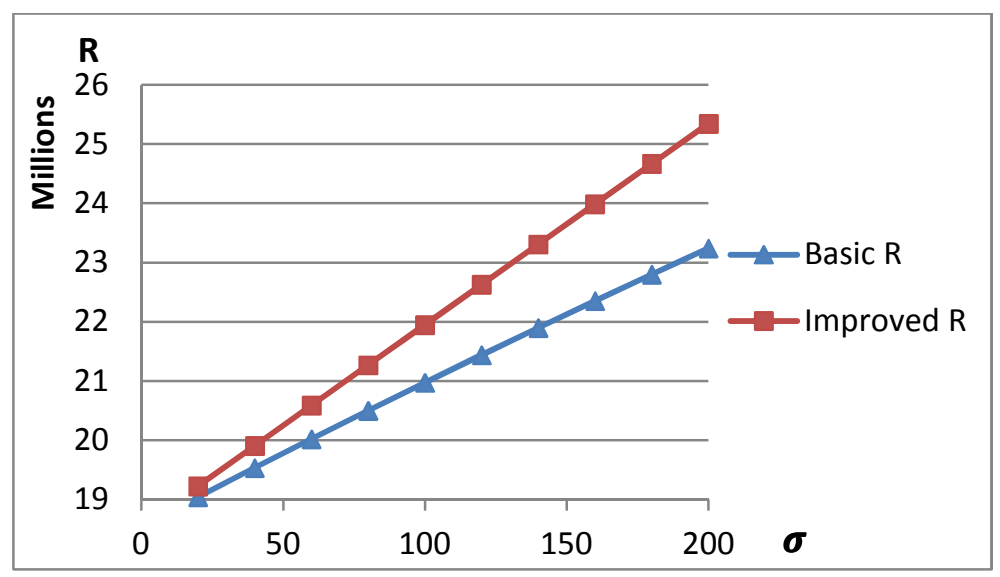

Figure 7. Total cost as $\sigma_{x}$ increases

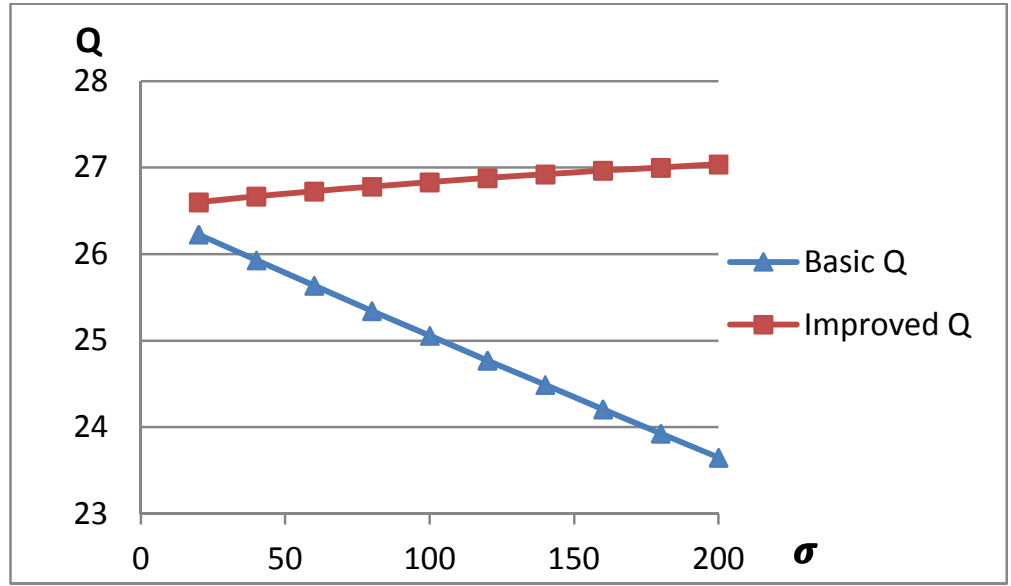

Figure 8. Optimal order quantity as $\sigma_{x}$ increases

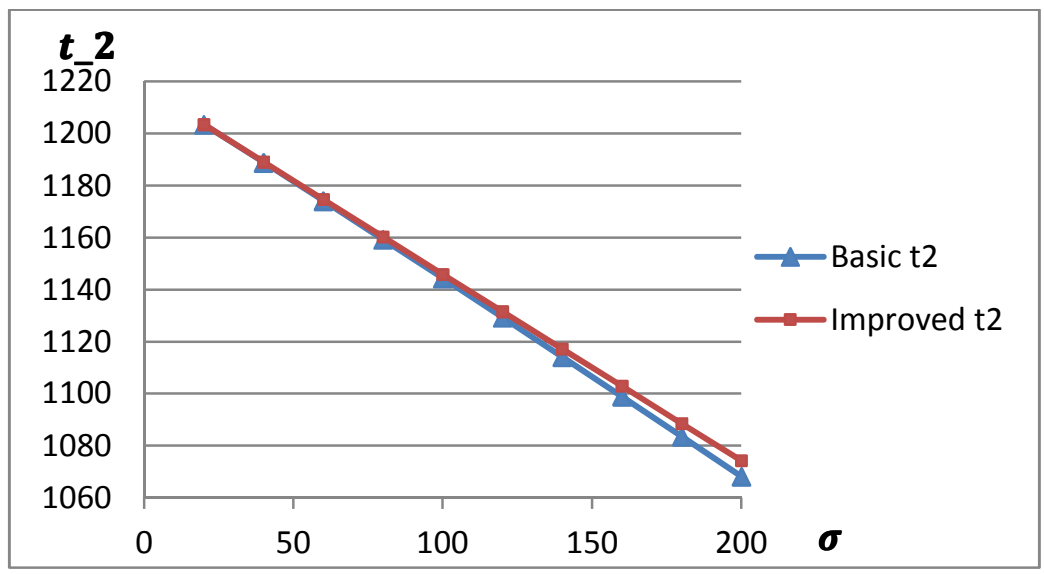

Figure 9. Optimal inventory replenishment time as $\sigma_{x}$ increases 


\section{Concluding Remarks and Future Work}

In this paper, by using the airline industry as the background, we have developed two mathematical models to solve a single PN spare parts inventory management problem, where demands come from installed part failures. We aim to establish an efficient inventory policy that aims to minimize the total cost of stock outs and holding spare parts inventory. Our models aim to reduce downtime due to spare parts shortage and excessive inventory holding cost by introducing parts failures distribution and triggering advanced orders at a proper time with a proper quantity. Compared with traditional forecast methods based on historical data, our models are more reasonable because they consider parts aging and focus on impending demands. Computational results indicate that our proposed basic inventory model can lead to a significant reduction in inventory cost, ranging from $5.68 \%$ to $98.03 \%$ in the first example, and $45.93 \%$ to $93.06 \%$ in the second example. We also observed that the values of $t_{2}$ in the two models always remain at the same level no matter how we change $\mu_{x}, \sigma_{x}$, or $\mu_{z}, \sigma_{z}$. Furthermore, compared with $\mu_{\mathrm{x}}$ and $\mu_{\mathrm{z}}$, increased $\sigma_{\mathrm{x}}$ and $\sigma_{\mathrm{z}}$ will widen the gap between the two models, in terms of both the minimum total cost (R) and the optimal order quantity (Q). The most dramatic gap in $Q$ appears when we change the value of $\sigma_{x}$, with a percentage error of $12.54 \%$, while this also happens to $\mathrm{R}$ with a percentage error of $8.3 \%$ (See Table 6). An insight drawn from the numerical analyses is that the basic model can be used as a reasonable substitute for inventory planning due to its easier operation. Moreover, the calculation result of $t_{2}$ from the basic model can be used to approximate the result of the improved model which can effectively simplify the calculation process.

It is assumed that the parts failure follows normal distribution in the improved model and the solution approaches, though the basic model developed is independent of the distribution. As stated in Section 3.2.1, the normal distribution is widely used to describe the statistical process of parts failure. However, with the different distributions, the advanced model can be revised with using the suitable distribution function, and the model can be solved either by numerical iterative approaches or by optimization solvers, depending on the distribution function. In case of Poisson distribution, the models can be simplified. It would be interesting to observe the impact of different distributions of parts failure on the inventory management, which is beyond the scope of this paper. 
The problem considered in this paper is for fixed horizon T. One of the future extensions of the research is to study the problem under a rolling horizon context taking past orders into account. In this situation, the running time for each part is different: some are new and some have been used for certain time in the system. One possible approach is still to employ the models and solution methods presented in the paper but we need update the failure distribution in the new period. For example, we calculate each part's failure time in terms of the mean time to failure - running time (set to 0 if negative); then we use a normal distribution to approximate the updated statistical data of parts failure. The order quantity should deduct the remaining inventory ordered in the last period.

Another extension of the research is to investigate the problem for multiple given part numbers with a budget constraint. It is common and necessary to maintain large numbers of different parts in airline industries. In the case the model will be more complex and new solution approaches are needed to solve the problem, especially for large scale problems. 


\section{References}

Allen, S.G. and D'esopo, D.A., 1968. An ordering policy for repairable stock items. Operation Research, $16(3), 482-489$.

Armstrong, M. and Atkins, D., 1996. Joint optimization of maintenance and inventory policies for a simple system. IIE Transactions,28 (5), 415-424.

Batchoun, P., Ferland, J.A. and Cléroux, R., 2003. Allotment of aircraft spare parts using genetic algorithms. Pesquisa Operacional, 23(1), 141-159.

Byington, C., Roemer, M.J., Galie, T., 2002. Prognostic enhancements to diagnostic systems for improved condition-based maintenance. Proceedings of IEEE Aerospace Conference, vol. 6, Big Sky, USA, March 9-16, pp. 2815-2824.

Campbell, H.S., 1963. The Relationship of Resource Demands to Air Base Operations. RAND, Santa Monica.

Deshpande, V., Iyer, A. V. and Cho, R., 2006. Efficient supply chain management at the U.S Coast Guard using part-age dependent supply replenishment policies. Operation Research, 54 (6), 1028-1040

deSmidt-Destombes, K.S., van der Heijden, M.C. and van Harten, A., 2007. Availability of k-out-of-N systems under block replacement sharing limited spares and repair capacity. International Journal of Production Economics, 107, 404-421

Ghobbar, A.A. and Friend, C.H., 2002. Sources of intermittent demand for aircraft spare parts within airline operations. Journal of Air Transport Management,8, 221-231.

Ghobbar, A.A. and Friend, C.H., 2003. Evaluation of forecasting methods for intermittent parts demand in the field of aviation: a predictive model. Computers and Operations Research, 30, 2097-2114.

Ghobbar, A.A. and Friend, C.H., 2004. The material requirements planning system for aircraft maintenance and inventory control: a note. Journal of Air Transport Management 10, 217-221.

Kiyak, E., 2012. The effects of aircraft preventive maintenance on reliability. International Journal of Applied Mathematics and Informatics, 6(1), 9-16.

MCTF, 2012. Airline Maintenance Cost: Executive Commentary - An Exclusive Benchmark Analysis (FY2010 data) by IATA's Maintenance Cost Task Force.

Muchiri, A.K. and Smit, K., 2011. Optimizing aircraft line maintenance through task re-clustering and 
interval de-escalation. Sustainable Research and Innovation Proceedings. Vol 3.

Natarajan, R., 1968. A reliability problem with spares and multiple repair facilities. Operation Research, 16, 1041-1057.

Regattieri,A., Gamberi,M., Gamberini,R. and Manzini,R., 2005. Managing lumpy demand for aircraft spare parts. Journal of Air Transport Management 11, 426-431.

Tuomas, R., Eemeli, K., Ville, A.M., Kai, V., Raimo, P.H., 2001. A simulation model for military aircraft maintenance and availability. 15th European Simulation Multi conference, Prague, Czech, 6.9.6.2001

Vaughan, T.S., 2005. Failure replacement and preventive maintenance spare parts ordering policy. European Journal of Operational Research, 161, 183-190.

Wang, W., 2012. A stochastic model for joint spare parts inventory and planned maintenance optimization. European Journal of Operational Research, 216, 127-139. 